\title{
Dispersive Liquid-Liquid Microextraction Combined With Electrothermal Atomic Absorption Spectrometry for the Speciation of Chromium in Environmental Samples
}

\author{
Yingjie Lii ${ }^{\mathrm{a}}$, Guangshun $\mathrm{Hou}^{\mathrm{b}, \mathrm{c} *}$, Zhiqiang Zhang ${ }^{\mathrm{a}}$, and Yajun Zhao ${ }^{\mathrm{c}}$ \\ a Department of Physics and Chemistry, Henan Polytechnic University, Jiaozuo 454003, P.R. China \\ b State Key Laboratory of Geological Processes and Mineral Resources, \\ China University of Geosciences, Wuhan, Hubei 430074, P.R. China \\ c School of Resources and Environment Engineering, Henan Polytechnic University, \\ Jiaozuo 454003, P.R. China
}

\section{INTRODUCTION}

In recent years, chromium has been widely used in tanning, electroplating, pigment production, and wood preservation. Consequently, large amounts of chromium compounds discharge into our environment which can affect the biology and ecology of the environment $(1,2)$. Chromium exists in nature in two relatively stable oxidation states, $\mathrm{Cr}$ (III) and $\mathrm{Cr}(\mathrm{VI})$. Trace amounts of Cr(III) are identified as an indispensable nutrient element for human and living organisms and play an important role in the maintenance of normal glucose, cholesterol, and the fatty acid metabolism. On the other hand, water soluble $\mathrm{Cr}(\mathrm{VI})$ is classified as a Class A carcinogen due to its ability to oxidize other species and has an adverse impact on the lungs, liver, and kidneys $(3,4)$. Due to these factors, an accurate and simple method for the determination of both chromium species is highly important for the protection of public health.

Several analytical techniques, including inductively coupled plasma optical emission spectrometry (ICP-OES) $(5,6)$, inductively coupled plasma mass spectrometry (ICP-MS) $(7,8)$, flame atomic absorption spectrometry (FAAS) (9), and electrothermal atomic absorption spectrometry (ETAAS) (10-12), have been proposed for the determination of chromium

*Corresponding author.

E-mail: guangshunhou@eyou.com

Fax: +0086-391-3987989

\section{ABSTRACT}

A new method for the speciation of chromium by dispersive liquid-liquid microextraction (DLLME), combined with electrothermal atomic absorption spectrometry (ETAAS), is presented and evaluated. Since Cr(III) forms complexes with $\mathrm{N}$ benzoyl-N-phenylhydroxylamine (BPHA) at $\mathrm{pH}$ 9.0, it was extracted into fine droplets of carbon tetrachloride (extraction solvent) with ethanol in aqueous solution, while $\mathrm{Cr}(\mathrm{VI})$ remained as free species in aqueous solution. After centrifugation, $\mathrm{Cr}$ (III) was determined in the sedimented organic phase. Cr(VI) was reduced to $\mathrm{Cr}$ (III) with hydrogen peroxide prior to the total determination of $\mathrm{Cr}$, which was based on subtracting $\mathrm{Cr}$ (III) from total chromium.

Under the optimized conditions and after extraction, the limit of detection (LOD) for Cr(III) was $0.01 \mathrm{ng} \mathrm{mL}^{-1}$, with an enrichment factor of 96. The relative standard deviation (RSD) for seven replicate determinations of $1.0 \mathrm{ng} \mathrm{mL}^{-1} \mathrm{Cr}$ (III) was $4.7 \%$. The developed technique was applied to the speciation of chromium in real water samples and the recoveries for the spiked samples were in the $94.5-107.1 \%$ range. For validation, two certified reference materials of water samples (GBW08607 and GBW08608) were analyzed, and the results obtained were in good agreement with the certified values. species in different samples. Since chromium concentrations in environmental samples are very low (as low as $\mathrm{ng} \mathrm{mL}^{-1}$ ), various separation and preconcentration procedures have been used in combination with the above-mentioned techniques to obtain accurate, reliable, and sensitive results.

The development of miniaturized and environmentally friendly methods for sample preparation has become an important trend in the field of analytical chemistry. Consequently, different microextraction systems have been developed. As a miniaturizing liquid-liquid extraction (LLE) methodology, liquid phase microextraction (LPME) has attracted considerable attention because it incorporates sampling, extraction, concentration, and sample introduction into a single virtually solvent-free step, and, moreover, it provides high sensitivity and eliminates the possibility of carry-over effects. Since the introduction of the first paper on LPME in 1996 (13), different approaches of LPME, such as single-drop microextraction (SDME) $(14,15)$, hollow fiber liquid phase microextraction (HF-LPME) (16), and dispersive liquid-liquid microextraction (DLLME) $(17,18)$, have been developed. It should be pointed out that the former two LPME methods require careful and elaborate manual operations since they are susceptible to droplet breakup and air bubble formation during fast stirring. In addition, equilibration between the aqueous solution and the droplet could not be attained after a long analysis time in most cases (19). 
As a novel modality of LPME, DLLME is based on ternary component solvent systems, such as cloud point extraction (CPE) and homogeneous liquid-liquid extraction (HLLE). The first use of DLLME for the preconcentration of organic compounds was pioneered by Assadi and co-workers (20), who applied the method as a preconcentration step for polycyclic aromatic hydrocarbons (PAHs) prior to analysis by gas chromatography-flame ionization detection (GC-FID). In this method, the appropriate mixture of extraction and dispersion solvent is rapidly injected into the aqueous sample containing the analytes. This procedure forms a cloudy solution, which consists of fine droplets of the extraction solvent which are dispersed throughout the aqueous solution. Consequently, the analyte is directly extracted into the fine droplets of the extraction solvent (generally hydrophobic organic compounds) or after complex formation (usually metal ion reaction with a suitable chelating ligand). After extraction, phase separation is performed by centrifugation, the analytes of interest are extracted from the initial solution, and the settled phase is concentrated to a small volume. Compared to other LPME methods, the major advantages of DLLME are simplicity and speed of operation. And more importantly, this method can be applied under batch conditions and thus improves analytical efficiency. Up to now, DLLME has been applied to the determination of trace organic (21-24) and inorganic species (25-28) in different samples.

Several articles have reported the combination of DLLME systems with atomic spectrometric detectors for the analysis of chromium species in different samples $(9,29)$. Considering the poor sensitivity of FAAS and the high instrumental and analytical costs involved with ICPMS, ETAAS is an efficient alternative due to its excellent detection limits and low instrumental and operating costs. DLLME is a miniaturized sample pretreatment technique and ETAAS is a microamount sample detection technique. Therefore, DLLME combined with ETAAS would be a perfect combination. Furthermore, the organic matrix in the injection solution can be eliminated at least in part using appropriate ashing time and temperature. In this sense, ETAAS is a suitable method for the analysis of small volumes of organic phase obtained in DLLME schemes.

In this paper, a new method is proposed using a combination of DLLME with ETAAS for the speciation of chromium in environmental water samples. N-benzoyl-N-phenylhydroxylamine (BPHA), a chelating agent which originates stable complexes with a number of metals and has found numerous applications in trace element separation and preconcentration methods $(30,31)$, is used to extract Cr(III) into the organic phase, while Cr(VI) does not react with BPHA and allows speciation of the inorganic forms of the element. Several factors $(\mathrm{pH}$, extraction and dispersion solvent types and volume, concentration of the chelating agent, extraction time, ashing temperature and atomization temperature) influencing microextraction and the subsequent determination were investigated in detail. The proposed method was applied to the speciation of chromium in two certified

\section{Atomic Apectroscopy 1 Vol. 32(4), July/Augustl 2011}

reference materials (GBW08607 and GBW08608 water) and in different real water samples with satisfactory results.

\section{EXPERIMENTAL}

\section{Instrumentation}

A TAS-990 atomic absorption spectrometer, equipped with a deuterium lamp for background correction and a standard transversely heated graphite furnace (THGA) using graphite tubes with an integrated pyrolytically coated platform (Beijing Purkinje General Instrument Co. Ltd., Beijing, P.R. China), was employed. Deuterium lamp background correction was used to correct the non-specific absorbance. A chromium hollow cathode lamp (Hengshui Ningqiang Light Source Factory, Hengshui, P.R. China) was the radiation source at $357.9 \mathrm{~nm}$, with a slit width of $0.4 \mathrm{~nm}$. Argon $99.99 \%$ was used as the protective and purge gas. The graphite furnace temperature program for the determination of chromium is listed in Table I. A TDL-80-2C centrifuge (Shanghai Anting Scientific Instrument Factory, Shanghai, P.R. China) was used to accelerate phase separation. The $\mathrm{pH}$ values were measured with a PHS-3B pH meter (Shanghai precision \& Scientific Instrument Co., Ltd., P.R. China) which is equipped with a combined glass electrode.

TABLE I

Graphite Furnace Temperature Program for the Determination of Cr

\begin{tabular}{lcccc}
\hline Step & $\begin{array}{c}\text { Temperature } \\
\left({ }^{\circ} \mathrm{C}\right)\end{array}$ & $\begin{array}{c}\text { Ramp Time } \\
(\mathrm{s})\end{array}$ & $\begin{array}{c}\text { Hold Time } \\
(\mathrm{s})\end{array}$ & $\begin{array}{c}\text { Ar Flow Rate } \\
\left(\mathrm{mL} \mathrm{min}^{-1}\right)\end{array}$ \\
\hline Drying & 100 & 10 & 10 & 450 \\
Ashing & 1000 & 10 & 15 & 450 \\
Atomization & 2300 & 0 & 4 & 0 \\
Cleaning & 2400 & 1 & 1 & 450 \\
\hline
\end{tabular}




\section{Standard Solutions and Reagents}

A Cr(III) stock standard solution of $1.0 \mathrm{mg} \mathrm{mL}^{-1}$ was prepared by dissolving appropriate amounts of $\mathrm{Cr}$ powder (AR, Shanghai Jingchun Industry Co., Ltd., Shanghai, P.R. China) in $\mathrm{HCl}(1: 1)$ and diluting to $100 \mathrm{~mL}$ with doubly distilled deionized water. A Cr(VI) stock standard solution of $1.0 \mathrm{mg} \mathrm{mL}^{-1}$ was prepared by dissolving the corresponding salt $\mathrm{K}_{2} \mathrm{Cr}_{2} \mathrm{O}_{7}$ (AR, Shanghai Jingchun Industry Co., Ltd., Shanghai, P.R. China) in doubly distilled deionized water. Working standard solutions were obtained by appropriate dilution of the stock standard solution just before use.

N-benzoyl-N- phenylhydroxylamine (BPHA) solution was prepared by dissolving appropriate amounts (AR, Shanghai Jingchun Industry Co., Ltd., Shanghai, P.R. China) in carbon tetrachloride (AR, Shanghai Reagent Factory, Shanghai, P.R. China).

The stock solutions of the interfering elements $\mathrm{K}^{+}$and $\mathrm{Na}^{+}$were prepared from their analytical reagents by dissolving $\mathrm{KCl}$ and $\mathrm{NaCl}$ (A.R., Shanghai Reagent Factory, Shanghai, P.R. China) in doubly distilled deionized water. The stock solutions of the interfering elements $\mathrm{Ca}^{2+}, \mathrm{Mg}^{2+}, \mathrm{Fe}^{3+}, \mathrm{Zn}^{2+}$, $\mathrm{Pb}^{2+}, \mathrm{Al}^{3+}, \mathrm{Cu}^{2+}$, and $\mathrm{Mn}^{2+}$ were prepared by dissolving certain amounts of their inorganic salts $\left[\mathrm{CaCl}_{2}, \mathrm{Mg}\left(\mathrm{NO}_{3}\right)_{2}, \mathrm{Fe}\left(\mathrm{NO}_{3}\right)_{3}, \mathrm{ZnCl}_{2}\right.$, $\mathrm{Pb}\left(\mathrm{NO}_{3}\right)_{3}, \mathrm{Al}\left(\mathrm{NO}_{3}\right)_{3}, \mathrm{CuCl}_{2}$, and $\mathrm{Mn}\left(\mathrm{NO}_{3}\right)_{2}$ ] (A.R., Shanghai Reagent Factory, Shanghai, P.R. China) in 2\% (w/v) $\mathrm{HCl}$. The stock solutions of the interfering anions $\mathrm{Cl}^{-}$and $\mathrm{SO}_{4}{ }^{2-}$ were prepared from their analytical reagents by dissolving certain amounts of $\mathrm{NH}_{4} \mathrm{Cl}$ and $\left(\mathrm{NH}_{4}\right)_{2} \mathrm{SO}_{4}$ in doubly distilled deionized water. All chemicals and reagents used in this study were of analytical reagent grade or higher purity and doubly distilled deionized water was used throughout.
Glass containers and all other immersed laboratory materials that could come in contact with the samples or standards were stored in $10 \%(\mathrm{v} / \mathrm{v})$ nitric acid and rinsed with doubly distilled deionized water prior to use.

Hydrogen peroxide was purchased from Shanghai Reagent Factory (Shanghai, P.R. China).

The certified reference materials (CRMs), GBW08607 and GBW08608 Water, were supplied by the National Institute of Metrology (NIM, Beijing, P.R. China).

\section{Dispersive Liquid-Liquid Microextraction Procedure}

A 7-mL amount of aqueous sample solution (or water sample) containing Cr(III) was placed in a 10-mL screw cap glass test tube. Then, $1.0 \mathrm{~mL}$ of ethanol (as dispersion solvent), containing $45 \mu \mathrm{L}$ of carbon tetrachloride (as extraction solvent) and $0.15 \%(\mathrm{w} / \mathrm{v})$ BPHA (as chelating reagent), was rapidly injected into the sample solution by using a 1.0-mL syringe. A cloudy solution formed in the test tube and separation of the phases was achieved by centrifugation at 4000 rpm for 5 minutes. After this step, five microliters of the sedimented phase at the conical bottom of the test tube was withdrawn into the microsyringe and injected directly into the graphite tube for analysis. The absorbance of chromium was recorded and peak height was measured for quantification.

\section{Sample Preparation}

Lake water samples ( $\mathrm{pH} 7.73$, Longyuan Lake, Jiaozuo, P.R. China) and pool water ( $\mathrm{pH} 8.73$, Henan Polytechnic University, Jiaozuo, P.R. China) were collected in a 50-mL polyethylene container. Local tap water ( $\mathrm{pH}$ 6.96) was collected after a 5-minute free outflow from the tap. All water samples were filtered through a $0.45-\mu \mathrm{m}$ membrane filter (Shanghai Xingya
Purification Material Factory, Shanghai, P.R. China). If analysis of the water samples was not carried out immediately, they were stored in polyethylene bottles at $4{ }^{\circ} \mathrm{C}$. The storage period was kept as short as possible.

A blank test was performed throughout this work. For preparation of the blank samples, the above solution, subjected to DLLME without the target analyte, was used as the procedural blank. The concentration values of both the Cr(III) and total chromium were obtained by substracting the procedural blank values.

\section{Determination of $\mathrm{Cr}$ (III) and Cr(VI)}

(a) Cr(III): After the DLLME procedure, $5 \mu \mathrm{L}$ of the organic phase was directly introduced into the graphite tube for determination.

(b) Total Cr: For total chromium determination, 30\% hydrogen peroxide has to be added and heated for 10 minutes in a boiling water bath prior to the DLLME procedure (32), then it was determined by ETAAS.

(c) Cr(VI): The concentration of Cr(VI) was calculated by subtracting $\mathrm{Cr}$ (III) from the total $\mathrm{Cr}$.

\section{RESULTS AND DISCUSSION}

\section{Optimization of ETAAS Conditions}

The appropriate pyrolysis and atomization steps are very important for reducing interference effects and enhancing analyte sensitivity. Therefore, the influence of pyrolysis temperature $\left(800-1600{ }^{\circ} \mathrm{C}\right)$ and atomization temperature (2000-2500 ${ }^{\circ} \mathrm{C}$ ) on the absorbance of chromium in the organic phase was investigated. Figure 1 shows that the absorbance of Cr visibly decreased when the pyrolysis temperature was higher than $1100{ }^{\circ} \mathrm{C}$ (Figure 1a). Therefore, a pyrolysis temperature of $1000{ }^{\circ} \mathrm{C}$ was chosen 
for the determination of $\mathrm{Cr}$ in this study. The effect of the pyrolysis time on the absorbance of chromium was also investigated. The results showed that the background signal decreased when the pyrolysis time (hold time) changed from 5 to 15 seconds; no appreciable improvements were observed at longer time periods. As a result, a pyrolysis time of 15 seconds was chosen.

As shown in Figure 1b, maximum absorbance of chromium was obtained when the atomization temperature varied from 2200 to $2500{ }^{\circ} \mathrm{C}$. The experimental results also showed that atomization time has little effect on the absorbance of chromium. Therefore, an atomization temperature of $2300^{\circ} \mathrm{C}$ and an atomization time of 4 seconds were selected for the determination of chromium.

\section{Optimization of DLLME Parameters \\ Effect of $p H$}

It is well known that the $\mathrm{pH}$ of the sample solution plays an important role in metal chelate formations and their subsequent extraction. In this part of the study, the medium $\mathrm{pH}$ was evaluated for its effect on the absorbance of $\mathrm{Cr}$ (III) and $\mathrm{Cr}(\mathrm{VI})$. As can be seen from Figure 2, maximum absorbance of $\mathrm{Cr}$ (III) was obtained with the $\mathrm{pH}$ ranging from 8.5 to 10 , whereas $\mathrm{Cr}(\mathrm{VI})$ was not extracted in this $\mathrm{pH}$ range. $\mathrm{A}$ low extraction efficiency of $\mathrm{Cr}$ (III) was observed when the $\mathrm{pH}$ was $<8.5$ since an incomplete or even no chelation reaction between $\mathrm{Cr}(\mathrm{III})$ and BPHA takes place. Thus, pH 9.0 was adopted for the selective separation of different species of chromium.

\section{Effect of Type and Volume of Extraction Solvent}

Choosing the most suitable extraction solvent is very important to achieve efficient extraction and good selectivity of the target com- pounds. This solvent should have a higher density than water, a high extraction capability of the analytes, and low solubility in water. For this purpose, the effects of chloroform $\left(\mathrm{CHCl}_{3}\right)$, carbon tetrachloride $\left(\mathrm{CCl}_{4}\right)$, and bromobenzene $\left(\mathrm{C}_{6} \mathrm{H}_{5} \mathrm{Br}\right)$ were compared for the extraction of chromium. A series of sample solutions were studied by using $1 \mathrm{~mL}$ of ethanol and $45.0 \mu \mathrm{L}$ of each solvent. Three replicate tests were subjected to DLLME under the same conditions. The results showed that the analyte signal with $\mathrm{CCl}_{4}$ as the extraction solvent was higher than that with chloroform and bromobenzene (see Figure 3). Therefore, $\mathrm{CCl}_{4}$ was selected as the extraction solvent for subsequent experiments.

To evaluate the influence of the extraction solvent volume, solutions with different volumes of $\mathrm{CCl}_{4}$ (45-150 $\mu \mathrm{L}$ ) were subjected to the same DLLME procedure (the volume of ethanol was fixed at $1.0 \mathrm{~mL}$ ). Figure 4 shows that by increasing the volume of $\mathrm{CCl}_{4}$ from 45 to $150 \mu \mathrm{L}$, the analyte signal decreases accordingly. So, $45 \mu \mathrm{L}$ of extraction solvent was selected for further studies.

\section{Effect of Type and Volume of Dispersion Solvent}

The most important factor in the selection of the dispersion solvent for DLLME procedures is its miscibility with the extraction solvent and the aqueous phases. For the sake of acquiring the most suitable dispersion solvent, four different solvents were tested: acetone, acetonitrile, methanol, and ethanol. The effect of these solvents on the absorbance of $\mathrm{Cr}$ was investigated using $1.0 \mathrm{~mL}$ of each solvent containing $45.0 \mu \mathrm{L}$ of $\mathrm{CCl}_{4}$ as the extraction solvent. As can be seen from Figure 5, the analyte signal with methanol and ethanol was higher than with acetone and acetonitrile. Ethanol was selected as

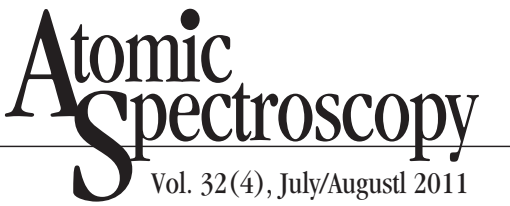

dispersion solvent in the following experiments due to its low toxicity.

The volume of the dispersion solvent is an important factor in DLLME. The effect of dispersion solvent volume on the absorbance of chromium was investigated with solutions containing different volumes of ethanol (ranging from 0.2 to $2.0 \mathrm{~mL}$ ) and containing $45.0 \mu \mathrm{L}$ of carbon tetrachloride. The results (Figure 6) show that maximum absorbance of $\mathrm{Cr}$ was obtained with $1.0 \mathrm{~mL}$ of ethanol. At the low volume of ethanol, carbon tetrachloride was not completely dispersed and the analyte signal was low. Similarly, the slight decrease in absorbance in a high volume of ethanol was due to an increase in solubility of the chromium complex in the aqueous solution containing a high percentage of ethanol.

\section{Effect of BPHA Concentration}

In this work, BPHA was used as the chelating agent due to the highly hydrophobic nature of its metal complexes. Figure 7 shows how the amount of BPHA influences the absorbance of chromium. As can be seen, the absorbance of $\mathrm{Cr}$ (III) increased rapidly with an increase in APDC from 0.01 to $0.05 \%(\mathrm{w} / \mathrm{v})$, then remained constant with a further increase of BPHA from 0.05 to $0.3 \%$ (w/v). Considering the competitive complexation with other metal ions in practical cases, $0.15 \%(\mathrm{w} / \mathrm{v})$ BPHA was selected for further research.

\section{Effect of Extraction Time}

Extraction time is an important factor since it influences extraction efficiency and speed of analysis. In DLLME, extraction time is defined as the time when the mixture of disperser (ethanol) and extraction solvent (carbon tetrachloride) is injected into the aqueous sample and the centrifugation cycle starts. Keeping the solution at room temperature, the effect of extraction 


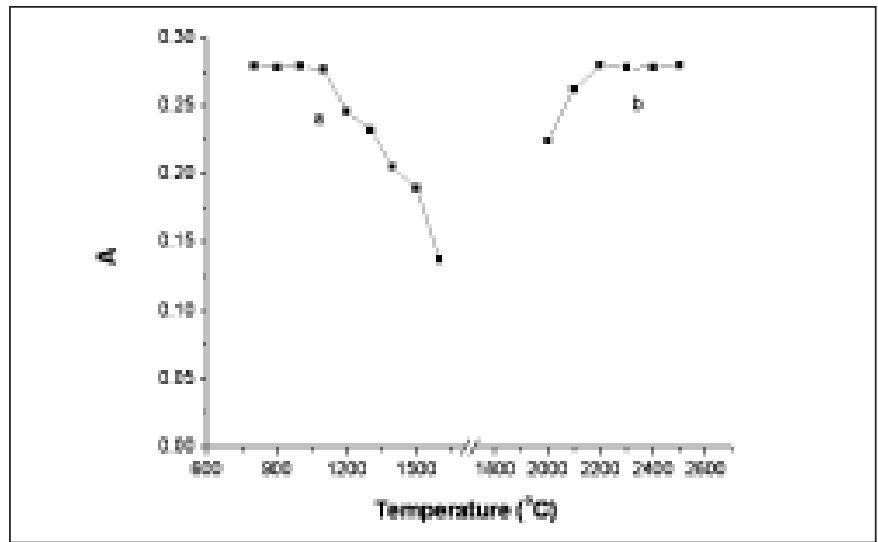

Fig. 1. Ashing (a) and atomization (b) curves of Cr(III) in the organic phase. Conditions: Cr(III), $100 \mathrm{ng} m L^{-1} ;$ BPHA, $0.15 \%$ $(w / v)$.

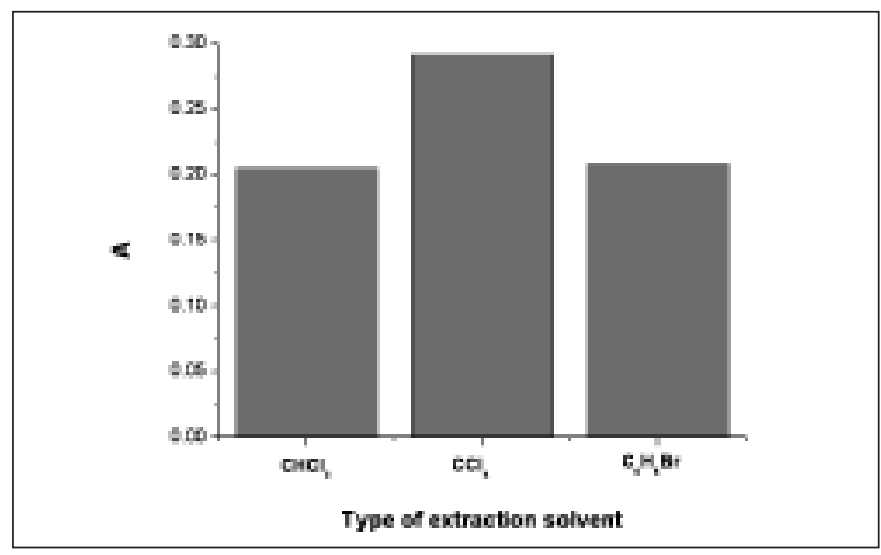

Fig. 3. Effect of type of extraction solvent on the absorbance of Cr(III). Conditions: $7.0 \mathrm{~mL}$ of sample solution; $\mathrm{Cr}$ (III), $1.0 \mathrm{ng}$ $m L^{-1} ;$ pH 9.0; BPHA, 0.15\% (w/v); dispersion solvent (ethanol) volume, $1.00 \mathrm{~mL}$; extraction solvent, $\mathrm{CHCl}_{3}, \mathrm{CCl}_{4}, \mathrm{C}_{6} \mathrm{H}_{5} \mathrm{Br}$.

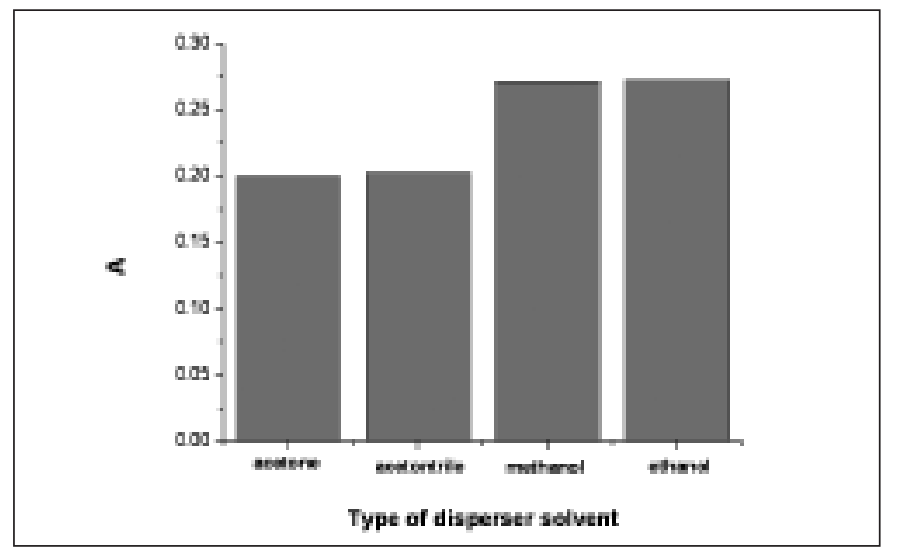

Fig. 5. Effect of type of dispersion solvent on the absorbance of Cr(III). Conditions: $7.0 \mathrm{~mL}$ of sample solution; Cr(III), $1.0 \mathrm{ng}$ $m L^{-1} ;$ pH 9.0; ВРHA, $0.15 \%(w / v)$; extraction solvent $\left(\mathrm{CCl}_{4}\right)$ volume, $45 \mu \mathrm{L}$; dispersion solvent, acetone, acetonitrile, methanol, and ethanol.

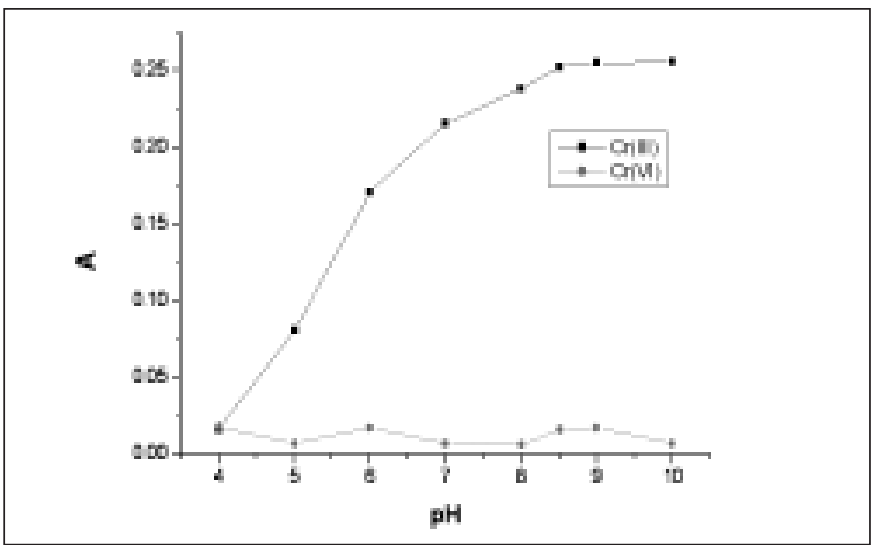

Fig. 2. Effect of $p H$ on the absorbance of Cr(III) and Cr(VI). Conditions: $7.0 \mathrm{~mL}$ of sample solution; $\mathrm{Cr}(\mathrm{VI})$ and $\mathrm{Cr}(\mathrm{III})$, $1.0 \mathrm{ng} \mathrm{mL}^{-1}$; BPHA, $0.15 \%(\mathrm{w} / \mathrm{v})$; dispersion solvent (ethanol) volume, $1.00 \mathrm{~mL}$; extraction solvent $\left(\mathrm{CCl}_{4}\right)$ volume, $45 \mu \mathrm{L}$.

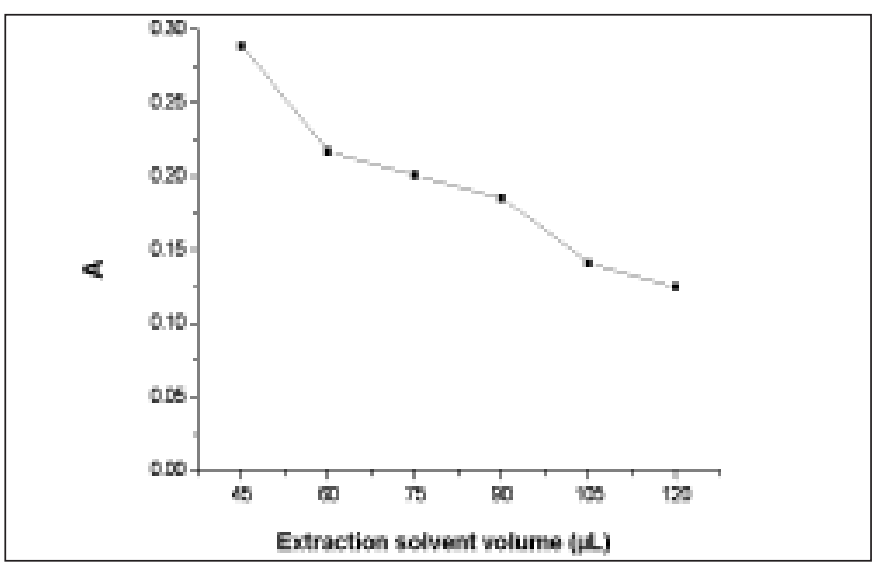

Fig. 4. Effect of extraction solvent volume on the absorbance of Cr(III). Conditions: $7.0 \mathrm{~mL}$ of sample solution; $\mathrm{Cr}(\mathrm{III}), 1.0 \mathrm{ng}$ $m L^{-1} ;$ pH 9.0; ВPHA, $0.15 \%(w / v)$; dispersion solvent (ethanol) volume, $1.00 \mathrm{~mL}$; extraction solvent, $\mathrm{CCl}_{4}$.

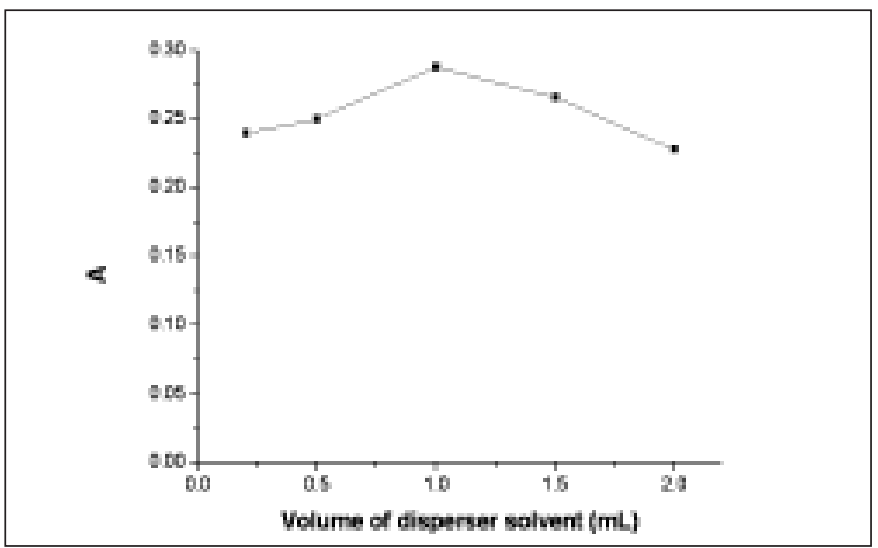

Fig. 6. Effect of dispersion solvent volume on the absorbance of Cr(III). Conditions: $7.0 \mathrm{~mL}$ of sample solution; Cr(III), 1.0 ng $\mathrm{mL}^{-1} ;$ pH 9.0; ВРHA, $0.15 \%(w / v)$; extraction solvent $\left(\mathrm{CCl}_{4}\right)$ volume, $45 \mu L$; dispersion solvent, ethanol. 


\section{Atomic

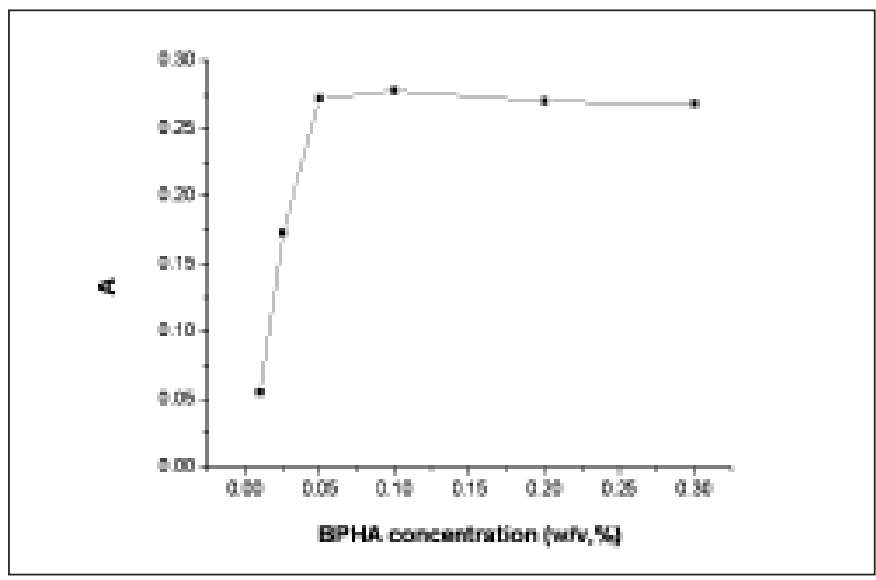

Fig. 7. Effect of BPHA concentration on the absorbance of Cr(III). Conditions: $7.0 \mathrm{~mL}$ of sample solution; Cr(III), $1.0 \mathrm{ng}$ $\mathrm{mL}^{-1}$; $\mathrm{pH}$ 9.0; dispersion solvent (ethanol) volume, $1.00 \mathrm{~mL}$; extraction solvent $\left(\mathrm{CCl}_{4}\right)$ volume, $45 \mu \mathrm{L}$.

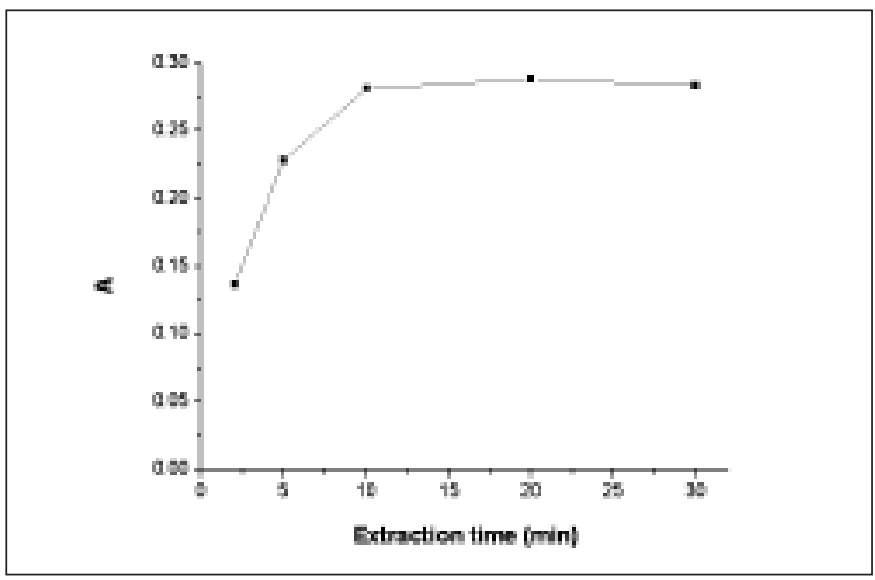

Fig. 8. Effect of extraction time on the absorbance of Cr(III).

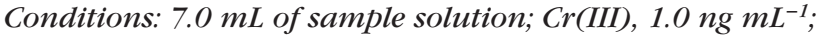
pH 9.0; ВРHA, 0.15\% (w/v);dispersion solvent (ethanol) volume, $1.00 \mathrm{~mL}$; extraction solvent $\left(\mathrm{CCl}_{4}\right)$ volume, $45 \mu \mathrm{L}$. time was examined ranging from 2 to 30 minutes using the same experimental conditions. Figure 8 shows that the analytical signal enhanced with an increase in extraction time from 2 to $10 \mathrm{~min}$ utes; maximum absorbance was obtained using from 10 to $30 \mathrm{~min}$ utes for Cr(III). To improve analytical efficiency, 10 minutes was selected as the extraction time.

\section{Interferences}

In order to demonstrate the selectivity of the developed method for the determination of $\mathrm{Cr}$ (III), the effects of common coexisting ions were investigated. Solutions of $1.0 \mathrm{ng} \mathrm{mL}^{-1}$ of $\mathrm{Cr}$ (III) and the added coexisting ions were treated according to the recommended procedure under the optimized conditions. The tolerance limits of coexisting ions, which gave less than a $10 \%$ error for the determination of the analyte, were evaluated and the results are listed in Table II. As can be seen, $5000 \mu \mathrm{g} \mathrm{mL}^{-1}$ of $\mathrm{Na}^{+}$ and $\mathrm{K}^{+} ; 100 \mu \mathrm{g} \mathrm{mL}^{-1}$ of $\mathrm{Mg}^{2+}$ and $\mathrm{Ca}^{2+} ; 50 \mu \mathrm{g} \mathrm{mL}^{-1}$ of $\mathrm{Mn}^{2+}$ and $\mathrm{Pb}^{2+}$; $10 \mu \mathrm{g} \mathrm{mL}-1$ of $\mathrm{Al}^{3+}, \mathrm{Zn}^{2+}, \mathrm{Fe}^{3+}, \mathrm{Cu}^{2+}$, and $\mathrm{SO}_{4}^{2-}$; and $7000 \mu \mathrm{g} \mathrm{mL}^{-1}$ of $\mathrm{Cl}^{-}$ had no obvious influence on the signal intensity of the analyte. Thus, it can be concluded that the devel-

TABLE II

Tolerance Limit of Coexisting Ions for the Determination of $1.0 \mathrm{ng} \mathrm{mL}^{-1} \mathrm{Cr}$ (III)

\begin{tabular}{lc}
\hline Coexisting Ions & Tolerance Limit of Ions $\left(\mu \mathrm{g} \mathrm{mL}{ }^{-1}\right)$ \\
\hline $\mathrm{Na}^{+}, \mathrm{K}^{+}$ & 5000 \\
$\mathrm{Mg}^{2+}, \mathrm{Ca}^{2+}$ & 100 \\
$\mathrm{Mn}^{2+}, \mathrm{Pb}^{2+}$ & 50 \\
$\mathrm{Al}^{3+}, \mathrm{Zn}^{2+}, \mathrm{Fe}^{3+}, \mathrm{Cu}^{2+}$ & 10 \\
$\mathrm{Cl}^{-}$ & 7000 \\
$\mathrm{SO}_{4}{ }^{2-}$ & 10 \\
\hline
\end{tabular}

oped method can be applied for the determination of $\mathrm{Cr}$ species in water samples.

\section{Analytical Performance}

Under the optimum experimental conditions described above, the calibration curve (obtained with a series of $\mathrm{Cr}$ (III) standard solutions ranging from $0.1-5 \mathrm{ng} \mathrm{mL} \mathrm{mL}^{-1}$ ), was linear, with a correlation coefficient (R2) of 0.9980 . The regression equation was $\mathrm{A}=0.182 \mathrm{C}+0.001$, where $A$ is the absorbance value and $\mathrm{C}$ is the concentration of $\mathrm{Cr}$ (III) in $\mathrm{ng} \mathrm{mL}^{-1}$. The limit of detection (LOD), calculated as the concentration of the analyte yielding a signal equivalent to three times the standard deviation of the blank value (for eight replicate measurements of a blank solution), was
$0.01 \mathrm{ng} \mathrm{mL}^{-1}$ for $\mathrm{Cr}(\mathrm{III})$, and the relative standard deviation (RSD) for seven replicate determinations of $1.0 \mathrm{ng} \mathrm{mL}^{-1}$ of $\mathrm{Cr}$ (III) was $4.7 \%$. The enrichment factor (EF), defined as the slope ratio of the two calibration standard curves with and without microextraction, was 96 for Cr(III).

A comparison of the performance (LOD, RSD, and cost) of the proposed work with some other sensitive methods based on extraction and preconcentration for the speciation of chromium is provided in Table III. It can be seen that (a) the LOD of the proposed method is much lower than obtained by SPEETAAS $(34,35)$, CME-ICP-MS (8), DLLME-FAAS (9), DLLME-ETAAS (29); and it is comparable with the 
LOD obtained by CPE-ICP-DRC-MS (33); (b) the precision (\%RSD) is better than with DLLME-ETAAS (29), comparable with SPE-ETAAS (35), and worse than CME-ICP-MS, DLLME-FAAS, CPE-ICP-DRC-MS, SPE-ETAAS $(8,9,33,34)$; (c) the cost of the developed method is comparable with DLLME-ETAAS, SPEETAAS $(29,34,35)$, lower than CME-ICP-MS, CPE-ICP-DRC-MS $(8,33)$, and higher than DLLMEFAAS (9). These comparisons may be of interest to routine laboratories performing trace element speciation.

\section{Validation and Application of the Proposed Method}

To evaluate the accuracy of the proposed method, two certified reference materials (GBW08607 and GBW08608 Water) were analyzed. The determined values for both inorganic chromium species, $\mathrm{Cr}$ (III) and $\mathrm{Cr}(\mathrm{VI})$, were obtained after subtracting the blank values. The results listed in Table IV indicate that only Cr(III) was detected and the obtained values are in good agreement with the certified values. This is consistent with the report of Wu et al. (10), who found that chromium existed as Cr(III) in two NIM water certified reference materials.

For further verification of the accuracy of the method, recovery tests were performed for $\mathrm{Cr}(\mathrm{III})$ and $\mathrm{Cr}(\mathrm{VI})$ in the two certified reference materials. The results listed in Table IV show that the recoveries for the spiked CRMs were $95.8-103.3 \%$ for $\mathrm{Cr}(\mathrm{III})$ and 97.4 - 104.3\% for Cr(VI), respectively.

The proposed method was also applied for the determination of $\mathrm{Cr}(\mathrm{III}) / \mathrm{Cr}(\mathrm{VI})$ in different real water samples (lake water, tap water, pool water). The analytical results together with the recoveries for the spiked samples are listed in Table V. It can be concluded that (a) the
TABLE III Analytical Characteristics of Different Extractive Methods

\begin{tabular}{lcccc}
\hline Method & $\begin{array}{c}\text { LOD } \\
\left(\mathrm{ng} \mathrm{mL}^{-1}\right)\end{array}$ & $\begin{array}{c}\text { RSD } \\
(\%)\end{array}$ & Cost & References \\
\hline CPE-ICP-DRC-MS & 0.01 & 3.0 & +++ & 33 \\
SPE-ETAAS & 0.015 & 3.2 & ++ & 34 \\
CME-ICP-MS & 0.074 & 3.9 & +++ & 8 \\
SPE-ETAAS & 0.34 & 4.6 & ++ & 35 \\
DLLME-FAAS & 0.07 & 2.0 & + & 9 \\
DLLME-ETAAS & 0.07 & 9.2 & ++ & 29 \\
DLLME-ETAAS & 0.01 & 4.7 & ++ & This work \\
\hline
\end{tabular}

CPE-ICP-DRC-MS: cloud point extraction-inductively coupled plasma dynamic reaction cell mass spectrometry;

SPE-ETAAS: solid phase extraction-electrothermal atomic absorbance spectrometry; CME-ICP-MS: capillary microextraction-inductively coupled plasma mass spectrometry.

"+ + " means "expensive"

"+ + means "normal"

"+ means "inexpensive"

TABLE IV

Analytical Cata of Cr Speciation in Certified Reference Materials (mean $\pm \mathrm{SD}, \mathrm{n}=3)$

\begin{tabular}{lrrrrrrr}
\hline Sample & $\begin{array}{c}\text { Certified } \\
\left(\mathrm{ng} \mathrm{mL}^{-1}\right)\end{array}$ & \multicolumn{2}{c}{$\begin{array}{c}\text { Added } \\
\left(\mathrm{ng} \mathrm{mL}^{-1}\right)\end{array}$} & \multicolumn{2}{c}{$\begin{array}{c}\text { Determined } \\
\left(\mathrm{ng} \mathrm{mL}^{-1}\right)\end{array}$} & \multicolumn{2}{c}{$\begin{array}{c}\text { Recovery } \\
(\%)\end{array}$} \\
\hline & & $\mathrm{Cr}(\mathrm{III})$ & $\mathrm{Cr}(\mathrm{VI})$ & $\mathrm{Cr}(\mathrm{III})$ & $\mathrm{Cr}(\mathrm{VI})$ & $\mathrm{Cr}(\mathrm{III})$ & $\mathrm{Cr}(\mathrm{VI})$ \\
\hline $\begin{array}{l}\text { GBW08607 } \\
\text { Water }\end{array}$ & $523 \pm 10$ & 0 & 0 & $515 \pm 13$ & $\mathrm{ND}$ & - & - \\
& & 500 & 500 & $1048 \pm 22$ & $487 \pm 10$ & 103.3 & 97.4 \\
GBW08608 & & & & & & & \\
Water & $33.5 \pm 2.0$ & 0 & 0 & $32.4 \pm 1.7$ & $\mathrm{ND}$ & - & - \\
& & 30 & 30 & $59.8 \pm 2.3$ & $31.3 \pm 1.8$ & 95.8 & 104.3 \\
\hline
\end{tabular}

ND: not determined.

TABLE V

Analytical Data of Cr Species Determined in Real Water Samples (mean \pm SD, $\mathbf{n}=3$ )

\begin{tabular}{lllllrr}
\hline Sample & $\begin{array}{c}\text { Added } \\
\left(\mathrm{ng} \mathrm{mL} \mathrm{mL}^{-1}\right)\end{array}$ & \multicolumn{2}{c}{$\begin{array}{c}\text { Determined } \\
\left(\mathrm{ng} \mathrm{mL}^{-1}\right)\end{array}$} & \multicolumn{2}{c}{$\begin{array}{c}\text { Recovery } \\
(\%)\end{array}$} \\
\hline \multirow{2}{*}{ Lake } & $\mathrm{Cr}(\mathrm{III}) \mathrm{Cr}(\mathrm{VI})$ & $\mathrm{Cr}(\mathrm{III})$ & $\mathrm{Cr}(\mathrm{VI})$ & $\mathrm{Cr}(\mathrm{III})$ & $\mathrm{Cr}(\mathrm{VI})$ \\
& 0.0 & 0.0 & $0.62 \pm 0.04$ & $0.41 \pm 0.02$ & - & - \\
& 0.3 & 0.3 & $0.91 \pm 0.06$ & $0.74 \pm 0.04$ & 98.9 & 104.2 \\
& 0.6 & 0.6 & $1.28 \pm 0.07$ & $1.02 \pm 0.05$ & 104.9 & 101.0 \\
Tap & 0.0 & 0.0 & $0.25 \pm 0.01$ & $0.18 \pm 0.01$ & - & - \\
& 0.3 & 0.3 & $0.52 \pm 0.03$ & $0.51 \pm 0.02$ & 94.5 & 106.3 \\
& 0.6 & 0.6 & $0.91 \pm 0.06$ & $0.74 \pm 0.04$ & 107.1 & 94.9 \\
Pond & 0.0 & 0.0 & $0.34 \pm 0.02$ & $0.27 \pm 0.01$ & - & - \\
& 0.3 & 0.3 & $0.62 \pm 0.04$ & $0.58 \pm 0.02$ & 96.9 & 101.8 \\
& 0.6 & 0.6 & $0.99 \pm 0.06$ & $0.83 \pm 0.05$ & 105.3 & 95.4 \\
\hline
\end{tabular}


difference in concentration of the two inorganic Cr species is very small for all analyzed water samples; (b) the concentration of the low oxidation state species (Cr(III)) in all water samples was a little bit higher than that of the high oxidation state species (Cr(VI)); (c) the total inorganic $\mathrm{Cr}$ in these water samples is at the ng $\mathrm{mL}^{-1}$ level. The recovery is defined as the amount of analyte found in spiked samples divided by the sum of the original and the spiked amount, times 100 . The recoveries for the spiked water samples were $94.5-107.1 \%$ for the Cr species.

\section{CONCLUSION}

A new method of dispersive liquid-liquid microextraction combined with ETAAS has been described for the determination of chromium species in environmental water samples. The basis of the developed method is the use of ethanol as dispersion solvent and carbon tetrachloride as extraction solvent for the selective extraction of N-benzoyl-N-phenylhydroxylamine (BPHA) complexed Cr(III). Cr(VI) did not form a BPHA complex and was not extracted by the organic solvent as free species in the solution; thus, separation of Cr(III) and Cr(VI) could be realized. The proposed method is simple (does not require separation by chromatography), sensitive (good anti-disturbance ability), safe (minimum use of toxic organic solvent), low cost (inexpensive reagent), and rapid (batch operation mode). In addition, it has a low limit of detection for Cr(III) (0.01 $\left.\mathrm{ng} \mathrm{mL}^{-1}\right)$ and a high enrichment factor (96) for the analysis of a small volume $(7.0 \mathrm{~mL})$ of water sample. Moreover, further improvements of the detection limits are feasible by preconcentrating larger amounts of sample solution.

\section{ACKNOWLEDGMENTS}

Financial support from the National Natural Science Foundation of China (No. 41003015) and the State Key Laboratory of Geological Processes and Mineral Resources (No. GPMR201011) is gratefully acknowledged.

$\overline{\text { Received March 15, } 2011 .}$

\section{REFERENCES}

1. N.N. Meeravali, K. Madhavi, and S. J. Kumar, J. Anal. At. Spectrom. 26, 214 (2011).

2. M.S. Hosseini and F. Belador, J. Hazard. Mater. 165, 1062 (2009).

3. Y.J. Li, B. Hu, Z.C. Jiang, and Y.W. Wu, Anal. Lett. 39, 809 (2006).

4. M.S. El-Shahawi, S.S.M. Hassan, A.M. Othman, M.A. Zyada, and M.A. ElSonbati, Anal. Chim. Acta 534, 319 (2005).

5. C. Puls and A. Limbeck, J. Anal. At. Spectrom. 24, 1434 (2009).

6. W. Zhou, Y.Q. Chai, R. Yuan, J.X. Guo, and X. Wu, Anal. Chim. Acta 647, 210 (2009).

7. N.N. Meeravali and S.J. Jiang, Talanta 80, 173 (2009).

8. W.L. Hu, F. Zheng, and B. Hu, J. Hazard. Mater. 151, 58 (2008).

9. P. Hemmatkhah, A. Bidari, S. Jafarvand, M. R. Milani Hosseini, and Y. Assadi, Microchim. Acta 166, 69 (2009)

10. P. Wu, H. Chen, G.L. Cheng, and X.D. Hou, J. Anal. At. Spectrom. 24, 1098 (2009).

11. M.L. Chen, Y.N. Zhao, D.W. Zhang, Y. Tian, and J.H. Wang, J. Anal. At. Spectrom. 25, 1688 (2010).

12. H.N. Sedumedi, K.L. Mandiwana, P. Ngobeni, and N. Panichev, J. Hazard. Mater.172, 1686 (2009).

13. H. Liu and P. K. Dasgupta, Anal. Chem. 68, 1817 (1996).

14. A. Garbi, V. Sakkas, Y.C. Fiamegos, C.D. Stalikas, and T. Albanis, Talanta 82, 1286 (2010).

15. E.M. Martinis and R.G. Wuilloud, J. Anal. At. Spectrom. 25, 1432 (2010).

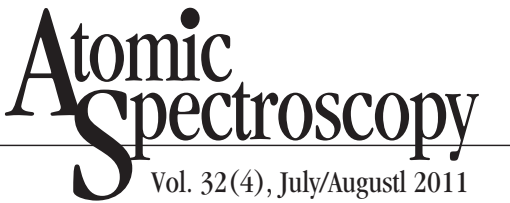

16. H.M. Jiang, B.Hu, B.B. Chen, and L.B. Xia, Anal. Chim. Acta 634, 15 (2009).

17. C. Pizarro, C. Saenz-Gonzalez, N. Perez-del-Notario, and J.M. Gonzalez-Saiz, OJ. Chromatogr. A 1217, 7630 (2010).

18. A.V. Herrera-Herrera, J. HernandezBorges, T.M. Borges-Miquel, and M.A. Rodriguez-Delgado, Electrophoresis 31, 3457 (2010).

19. L. Xu, C. Basheer, and H.K. Lee, J. Chromatogr. A 1152, 184 (2007).

20. M. Rezaee, Y. Assadi, M.R. Milani Hosseini, E. Aghaee, F.Ahmadi, and S. Berijani, J. Chromatogr. A 1116 , 1 (2006).

21. N. Negreira, I. Rodriguez, E. Rubi, and R. Cela, Anal. Bioanal. Chem. 398, 995 (2010).

22. H.Y. Yan, B.M. Liu, J.J. Du, and K.H. Row, Analyst 135, 2585 (2010).

23. P. Biparva, E. Ranjbari, and M.R. Hadjmohammadi, Anal. Chim. Acta 674,206 (2010).

24. L.J. He, X.L. Luo, X.M. Jiang, and L.B. Qu, J. Chromatogr. A 1217, 5013 (2010).

25. H. Abdolmohammad-Zadeh and G.H. Sadeghi, Talanta 81, 778 (2010).

26. S.R. Youse and F. Shemirani, Anal. Chim. Acta 669, 25 (2010).

27. N.M. Najafi, H. Tavakoli, R. Alizadeh, and S. Seidi, Anal. Chim. Acta 670, 18 (2010).

28. E. Molaakbari, A. Mostafavi, and D. Afzali, J. Hazard. Mater.185, 647 (2011).

29 H. Chen, P. Du, J. Chen, S.H. Hu, S.Q. Li, and H.L. Liu, Talanta 81, 176 (2010).

30. J. Li, L.F. Zhong, X.L. Tu, X.R. Liang, and J.F. Xu, Talanta 81, 954 (2010).

31. C.M. Xiong, M. He, and B. Hu, Geostand. Geoanal. Res. 33, 385 (2009).

32. J. S. Lu, J.J. Xu, J.Y. Tian, L. Shen, B. B. Hou, and T.W. Wu, Chinese J. Appl. Chem. 27, 1230 (2010).

33. N.N. Meeravali and Shiuh-Jen Jiang, Talanta 80, 173 (2009).

34. Y.Z. Ren, Z.F. Fan, and J.Y. Wang, Microchim Acta 158, 227 (2007).

35. E. Martendal, H.F. Maltez, and E. Carasek, J. Hazard. Mater. 161, 450 (2009). 